\title{
VIOLENCIA FAMILIAR: EL CASO DE LA PROVINCIA DEL GUAYAS-ECUADOR
}

Dra. Lidia Andrade Borrero*

\section{LA AGRESIVIDAD Y SUS TRASTORNOS}

L

a conducta agresiva es una manifestación básica en la actividad de los seres vivos. Su presencia en la totalidad del reino animal y los resultados de investigaciones al respecto le dan el carácter de fenómeno "multidimensional".

En el ser humano, la agresión comprende todos los comportamientos cuya finalidad es infligir daño físico o psíquico en los demás. Algunos opinan que la agresión es parte de un instinto no aprendido, vestigio de nuestro pasado que se desencadena por el dolor o la frustración. En otras palabras, parece ser que la frustración genera agresión solo en las personas que han aprendido a ser agresivas como medio para afrontar situaciones desagradables.

Brkowitz indica que "casi cualquier hecho desagradable puede desencadenar la agresión; así, la frustración es solo una de muchas experiencias desagradables que pueden dar lugar a agresiones". ${ }^{1}$

Freud consideraba que "la agresión es un impulso innato que se incrementa hasta que es liberado".?

El término agresividad hace referencia a un conjunto de patrones de actividad que pueden manifestarse con intensidad variable, que incluye desde la pelea física hasta los gestos o expresiones verbales que aparecen en el curso de cualquier negociación. Se presenta como una mezcla secuenciada de movimientos con diferentes patrones, orientados a conseguir distintos propósitos.

\footnotetext{
* Ex Decana y Subdecana de la Facultad de Ciencias Psicológicas, Ex Directora de la Maestría en Docencia Universitaria e Investigación Educativa, Profesora Principal de la Universidad de Guayaquil.

1 Un Nuevo Enfoque. - Psicología. - 7ma, Edición. - Concepto de varios autores. 1992

2 Sigmund Freud. - Obras Completas II. - Madrid - 1948
} 
En la persona concreta, puede manifestarse en cada uno de los niveles que integran al individuo: puramente físico, emocional, cognitivo y social. Su carácter es polimorfo.

Se puede presentar en el nivel físico, como lucha con manifestaciones corporales explícitas. En el nivel emocional, como rabia o cólera, manifestándose a través de la expresión facial y otros gestos corporales o en el cambio de tono y volumen del lenguaje. Desde un nivel cognitivo puede estar presente como fantasías destructivas, elaboración de planes agresivos o ideas de persecución propia o ajena.

El área social es el marco en el cual, de una manera o de otra, toma forma concreta la agresividad.

Como conducta social puede implicar lucha, pugnacidad y puede formar parte de las relaciones de poder - su misión, tanto en las situaciones diádicas como en los grupos, presenta elementos de ataque y retirada por ello se relaciona con otras conductas de autoprotección.

La agresividad es una potencialidad sobre la cual se aprende a lo largo de la vida. La coexistencia de factores biológicos y culturales es un hecho evidente y da cuenta de la capacidad humana para oponer resistencia: incluye aspectos fisiológicos, conductuales y vivenciales. La agresión puede adoptar diferentes formas: motoras, verbales, gestuales, posturales. Toda conducta agresiva tiene un origen (agresor) y un destino (agredido). Para que una conducta se considere agresiva debe tener el requisito de la intencionalidad, es decir, la intención por parte del agresor de ocasionar un daño.

Es importante tener en cuenta que los sujetos construyen permanentemente su realidad, adjudicándole significado y en función de lo cual se estructuran sus conductas. Dado que estos significados no son entidades estáticas e inmutables, el cambio es posible. Se podría decir que una persona agresiva es aquella que tiende a percibir los datos de la realidad como provocadores y amenazadores y frente a tal construcción cognitiva reacciona con conductas de ataque y defensa. 


\section{CARACTERÍSTICAS DE LA VIOLENCIA FAMILIAR.}

Esta agresividad degenera en violencia. Este término se refiere a un tipo de agresividad que está fuera o más allá de "lo natural" en el sentido adaptativo y se caracteriza por su ímpetu e intensidad.

Se debe también considerar lo que es un conflicto, ya que estos surgen de la interacción social como expresión de la diferencia de intereses, deseos y valores de quienes participan en ella: el conflicto se encuentra en cualquier interacción humana.

Dado que la presencia de conflictos en las relaciones interpersonales es inevitable, en lo que nos tenemos que detener es en el método utilizado para su resolución. No es difícil diferenciar el conflicto resuelto mediante la puesta en juego de conocimientos, aptitudes y habilidades comunicativas, y otro que se resuelve mediante la ejecución de poder y de autoridad.

La violencia es un fenómeno histórico relacionado con el desenvolvimiento social del ser humano. La razón de la violencia es la combinación de factores negativos entre el individuo y la sociedad.

Las razones más comunes son el abuso en el consumo de drogas y alcohol, la permisividad y excesiva tolerancia frente a la posesión de armas de fuego y la propagación indiscriminada de imágenes violentas o delictivas por los medios de comunicación, las cuales ayudan a generar, mantener y reforzar los comportamientos.

Sin embargo, la multiplicidad de las causas de la violencia hacen extenso su estudio. Durante la evolución como método de permanencia en el tiempo, bajo la premisa de sobrevivir ante agresores, tener dominio sobre territorios y alcanzar la supremacía en grupos sociales.

La violencia es una acción ejercida por una o varias personas, en donde se somete de manera intencional al maltrato, presión, sufrimiento, manipulación u otra acción que atente contra la integridad tanto física como psicológica y moral de cualquier persona o grupo social. 
Son tan múltiples las manifestaciones, características y participantes, que la violencia ha logrado un sitial importante en la atención de distintos especialistas como sociólogos, psicólogos, filósofos y, por consiguiente, el esfuerzo mantenido en su investigación para aclarar sus causas y efectos.

Las distintas sociedades en su evolución, no han sabido manejar la violencia. La agudización de las desigualdades económicas y políticas han funcionado como su trampolín con el incremento de la inequidad en el reparto de los recursos, lo que se refleja en ira y depresión, sentimientos que mal manejados se transforman en violencia. También son considerados como violencia: maltrato, sufrimiento físico y mental, manipulación, seducción, exclusión social, crítica destructiva, desprecio, abandono, insultos, entre otros.

\section{ANTECEDENTES FAMILIARES.}

La cultura familiar nos lleva a reflexionar sobre la familia, que ha sufrido en el transcurso de los últimos siglos un cambio estructural de gran importancia. En ella el ser humano busca amor, comprensión, ternura, respeto, seguridad, equilibrio emocional. A pesar de que cada uno de sus integrantes tiene sus características individuales, se intenta siempre vivir en armonía y canalizar las necesidades de cada uno de sus miembros. Sin embargo los resultados estadísticos acerca de la familia nos han demostrado que el alto índice de delincuencia tiene su origen en la influencia del ambiente familiar.

En la actualidad, la violencia puede provenir de factores como: condiciones de hacinamientos, desempleo, condiciones sociales, deplorables, pérdida de valores morales, frustraciones, marginalidad, descontento, entre otros.

Se considera a la violencia como una situación en la que alguien con más poder abusa de otra con menos poder. El término violencia familiar, alude a todas las formas de abuso que tiene lugar en las relaciones entre miembros de la familia. La relación de abuso es aquella en la que una de las partes ocasiona un daño físico y/o psicológico a otro miembro. Este daño se puede dar, ya sea por acción o por omisión; y se da en un contexto de desequilibrio de poder. 
Es necesario distinguir entre conflicto familiar y violencia familiar. Comportamientos normales como discusiones, peleas, controversias no conducen, necesariamente a comportamientos violentos para su resolución. Se podría definir a la violencia familiar como toda acción u omisión cometida en el seno de la familia por uno de sus miembros, que menoscaba la vida o la integridad física o psicológica o incluso la libertad de otro de sus miembros y que causa un serio daño al desarrollo de su personalidad.

Para establecer que en el seno de una familia existe un caso de violencia familiar, la relación de abuso debe ser crónica, permanente y periódica. Nos referimos entonces a la violencia familiar, a las distintas formas de relación abusiva que caracterizan un vínculo intrafamiliar.

En las familias en las que aparece la violencia familiar se puede advertir; generalmente, una organización jerárquica fija o inamovible. Además, sus miembros interactúan rígidamente, no pueden recortar su propia identidad, deben ser u actuar como el sistema familiar les impone.

Las personas sometidas a situaciones crónicas de violencia familiar presentan un debilitamiento de sus defensas físicas y psicológicas, lo que conduciría a padecer enfermedades psicosomáticas.

También estas personas muestran una disminución marcada en el rendimiento laboral, los/las niños/as y adolescentes tiene problemas de aprendizaje, trastornos de la conducta y problemas interpersonales. Los/as niños/as que fueron víctimas de violencia o se criaron dentro de este contexto, tienden a reproducirlos en sus futuras relaciones.

En la práctica el maltrato tiene a "naturalizarse", es decir, se torna cotidiano sobre todo a través de conductas violentas, que no son sancionadas como tales. Muchas personas que maltratan son considerados (y se consideran a sí mismos) como de mayor poder frente a quienes son considerados (se piensan a sí mismos) como de menor poder.

Cabe destacar que las personas que sufren estas situaciones suelen ocupar un lugar relativamente de mayor vulnerabilidad dentro 
del grupo familiar. En este sentido la violencia hacia los/as niños/as y las mujeres, estadísticamente reviste la mayor casuística.

También cabe numerar la violencia cruzada, cuando el maltrato pierde el carácter de aparente unidireccionalidad. Desde el punto de vista jurídico resulta difícil la comprobación. Cuando se trata de violencia física en su mayoría son lesiones leves, las cuales cuando dejan marcas desaparecen en más de 15 días.

Por lo general quienes padecen estas situaciones tienen reticencia a denunciar lo que ocurre. Los motivos de este recelo ocupan desde hace muchos años a investigadores y profesionales; por un lado, porque se mantiene una espera de un cambio espontáneo de quien agrede, por otro se aceptan las disculpas (típicas) y se creen las promesas que no se lo volverá a hacer (otro rasgo característico). También influye el temor al prejuicio social, las convicciones ético - religiosas, la dependencia económica, el miedo a represalias, la falta de esperanzas en la eficiencia de los trámites jurídicos.

Pero quizás el punto más crítico del razonamiento sobre el maltrato se evidencia en el sostenimiento del vínculo violento. En este sentido entran en consideración tanto el aplastamiento psíquico, la baja autoestima, la educación violenta, como también la consideración de suponer una relación signada de vicios o sistemas psíquicos o relacionales o un posible montaje estructural subjetivo que impide romper el tipo de relación.

Se debe considerar que la situación violenta no solo la padecen quienes sufren golpes o humillaciones, sino también quien propina esos mismos golpes y humillaciones.

Intervienen al respecto los modelos de organización familiar, las creencias culturales, los estereotipos respecto a supuestos roles relacionados y las maneras particulares de significar el maltrato.

Es el Estado el que debe velar por la protección de las personas involucradas, mediante acciones concretas tales como el dictado de leyes y demás normativas jurídicas y la generación de espacios educativos, de contención e intervención comunitaria. 
Cabe destacarse que la represión por parte del Estado al agresor no soluciona el problema, por lo que resulta esperable el fomento de una pronta asistencia psicológica hacia el, la, o los/as agresores/as que en muchos casos ejercen violencia solo en la intimidad familiar y privada, ya que en otros ámbitos poseen un comportamiento cordial y afectuoso.

Abuso, violencia o maltrato relacional son sinónimos de situaciones en donde aparece la violencia física (leve o grave) de manera repetida o la violencia emocional expresada en constantes insultos, amenazas, descalificaciones y/o prohibiciones para sentir, pensar o actuar de determinado modo, conformando un modo de convivir cotidiano que provee un repetido sentimiento de vivir una posición no deseada.

Actualmente se habla de que en uno de cada cinco hogares se practican relacione abusivas y una de cada tres parejas sería propensa a vivir este tipo de relaciones. Desgraciadamente nos enteramos de estos problemas cuando ya dejaron importantes secuelas en la salud mental y/o física de las personas. Es necesario saber que hay una progresión en la gravedad y la frecuencia del maltrato, por lo que mientras más pronto se haga algo efectivo para detener el deterioro personal y relacional, mayor será la posibilidad de cambio.

Los grupos sociales más propensos a ser víctimas de la violencia, son aquellos que física o mentalmente están en desventaja como: mujeres, niños, ancianos, enfermos mentales, minorías sociales, políticas y religiosas. Sin embargo, ninguna persona está exenta de la violencia ya que proviene de todos los sectores de la vida, de todas las culturas, de grupos de bajos o altos ingresos, de todas las edades, todas estas personas comparten sentimientos de impotencia, aislamiento, culpa, temor y vergüenza.

\section{TIPOS DE VIOLENCIA.}

1. Violencia física: se relaciona con el uso de la fuerza humana para deteriorar las condiciones de otro ser, objeto o así mismo, abarcando golpes, cachetadas, empujones, puntapiés, heridas por armas de fuego, blancas y todas aquellas acciones que van en detrimento de la vida. 
2. Violencia verbal y emocional: todos aquellos actos en los que una persona lastima psicológica y moralmente a otra, por medio de agresiones, gritos, desprecios, insultos, mentiras, irrespeto a la privacidad. Irrespeto a sus creencias e ideas, comentarios sarcásticos y burlas que exponen a la víctima al público, incluye expresiones como: "Eres inútil" o "No sirves para nada".

3. Violencia sexual: abarca desde los ataques sexuales directos mediante violaciones, hasta la incitación a realizar actos de índole sexual sin el consentimiento de la otra persona, pasando por la violencia verbal dirigida al sexo, piropos obscenos, entre otras.

\section{TIPOS DE VIOLENCIA FAMILIAR.}

a) Maltrato infantil, es cualquier acción u omisión, no accidental que provoque un daño físico o psicológico a un niño por parte de sus padres o cuidadores.

En el caso de los/as niños/as como en otros casos de violencia, también se da una relación de vulnerabilidad y claramente los menores muestran inferiores recursos para defenderse en relación con un adulto, además se debe considerar el daño emocional y los efectos a corto y a largo plazo que provocan los maltratos.

En ocasiones se trata de golpeadores que fueron maltratados en la propia infancia, los padres que perciben como justos los castigos aplicados o perciben la desproporción del castigo ofrecido por la supuesta falta cometida. Es admirable que los mismos adultos golpeadores suelan manifestar y percibir que han golpeado a sus hijos en muchas menos ocasiones de lo que realmente lo hacen.

Algunos adultos golpeadores suelen manifestar algún afecto posterior como arrepentimiento o lástima, en muchos casos se trata de padres que están a favor del castigo como medida disciplinaria y educativa. El castigo recibido por los adultos en la infancia suele guardar relación con el tipo de castigos físicos que se emplean para "corregir" a los/as hijos/as. Hay diferentes tipos de maltratos: 
Maltrato físico: se refiere a cualquier lesión infligida (hematomas, quemaduras, fracturas, lesiones de cabeza, envenenamientos), que no es accidental y que provoca un daño físico o enfermedad en un/a niño/a. Puede ser el resultado de uno o dos incidentes aislados o puede ser una situación crónica de abuso.

Los signos de abuso físico en un/a niño/a pueden ser los siguientes:

I Versión contradictoria entre el relato de los padres y las lesiones que presenta el/la niño/a, hematomas inexplicables.

${ }_{1}$ Cicatrices.

Marcas de quemaduras.

Marcas de mordeduras de la medida de un/a adulto/a.

El maltrato físico de niños/as no se asocia a ningún grupo étnico, sino que se manifiesta en todas las clases sociales, religiones y culturas; no hay una situación específica que determine la violencia familiar, sino un conjunto de factores que predisponen a que ocurra. Estos factores pueden ser: baja autoestima, necesidad de control sobre el entorno y sentimientos de inferioridad. Los/las niños/as que han sido maltratados necesitan ayuda psicológica para no repetir el esquema de abuso a otras personas.

Maltrato sexual: se refiere a cualquier implicación de niños y adolescentes, dependientes e inmaduros en cuanto a su desarrollo, en actividades sexuales que no comprenden plenamente y ante las cuales son incapaces de responder mediante un consentimiento informado.

Se podría definir al abuso sexual como el tipo de contacto sexual por parte de un adulto o tutor, con el propósito de lograr excitación y/o gratificación sexual.

La intensidad del abuso puede variar de la exhibición sexual a la violación. De todas las formas de abuso, el abuso sexual es el más difícil de reconocer y aceptar. A partir de los estudios estadísticos, se observa que una de cada cuatro niñas y uno de cada ocho niños serán sexualmente abusados antes de llegar a los 16 años. 
En más del $90 \%$ de casos el abusador será masculino y en más del $80 \%$ el abusador será una persona conocida por el/la niño/a.

Los signos de abuso sexual en niños/as o adolescentes son:

Llanto fácil sin ningún motivo.

1 Cambios bruscos en la conducta escolar.

Llegar temprano a la escuela y retirarse tarde.

Ausentismo escolar.

1 Conducta agresiva o destructiva.

Depresión crónica.

1 Conocimiento sexual y conducta inapropiada para la edad.

I Irritación.

1 Dolor y lesión en zona genital.

ı Temor al contacto físico.

En la mayoría de los casos los niños nunca comunican lo que está ocurriendo; los/as niños/as no inventan historias acerca de sus propio abuso sexual, por eso, en la medida que el/la niño/a se anima a decirlo, es preciso creerle.

Abandono y abuso emocional: generalmente se presenta bajo las formas de hostilidad verbal, como por ejemplo insultos, burlas, desprecio, críticas o amenazas de abandono; también aparece en la forma de constante bloqueo de las iniciativas infantiles por parte de algún miembro de la familia.

Todo esto provoca en el/la niño/a graves trastornos psicológicos.

Algunos indicadores de abuso emocional pueden ser:

1 Extremada falta de confianza en sí mismo.

1 Exagerada necesidad de ganar o sobresalir.

I Mucha agresividad o pasividad en el/la niño/a.

Los padres muchas veces abusan emocionalmente de sus hijos/as basados en buenas intenciones, por ejemplo, cuando quieren que sobresalgan en el colegio, en los deportes o en la vida social, pero a partir de estas buenas intenciones pueden presionarlos 0 avergonzarlos al punto d crearles un sufrimiento emocional crónico. 
Mientras que el abandono emocional puede ser desde un lugar pasivo, sin brindar afecto, apoyo y la valoración que todo niño/a necesita para crecer psicológicamente sano/a, la falta de respuestas a sus necesidades de contacto afectivo y una constante indiferencia a los estados emocionales del/la niño/a.

Abandono físico: es un maltrato pasivo y se presenta cuando las necesidades físicas del/la niño/a como alimentación, abrigo, higiene y protección no son atendidas en forma permanente por ningún miembro del grupo que convive con el/la niño/a.

Niños/as testigos de violencia: cuando los/as niños/as presencian situaciones crónicas de violencia entre sus padres, estos/as niños/as presenta trastornos muy similares a los que caracterizan a quienes son víctimas de abuso.

b) Violencia conyugal, este tipo de violencia es difícil que se haga visible hacia los demás, y se da cuando hay daños físicos o psicológicos. Cuando un hombre y una mujer conforman una pareja se produce el encuentro de las historias individuales y su interpretación. Cada uno llega con un bagaje propio de valores y creencias acerca de los conceptos "pareja" y "familia". Poco a poco la pareja construye un paradigma propio, es decir, un conjunto de premisas compartidas que emplearán para dar cuenta al mundo y coordinar sus actividades, recortando así, su sentido de identidad familiar.

Las personas interactúan en congruencia con su paradigma, y su vida en común evoluciona en forma coherente, pero a veces, la suma de ciertos procesos acaba con el funcionamiento coherente y equilibrado.

Este tipo de violencia tiene un ciclo de tres fases:

1. Fase de acumulación de tensión: es la fase en la que se produce una sucesión de pequeños episodios que llevan a roces permanentes entre la pareja, con un incremento constante de ansiedad y hostilidad. Tanto el hombre y la mujer se encierran en un circuito en el que están mutuamente pendientes de sus reacciones. 
2. Episodio agudo: donde la tensión alcanza su punto máximo: toda la tensión que se venia acumulando da lugar a una explosión de violencia, que puede variar en gravedad, oscilando desde un empujón hasta el homicidio. Se caracteriza por el descontrol y lo inevitable de los golpes. Las mujeres se muestran sorprendidas frente al hecho que se desencadena de manera imprevista, ante cualquier situación de la vida cotidiana.

3. Luna de miel: es la fase donde se produce el arrepentimiento del agresor, con disculpas y promesas de que nunca más va a ocurrir; pero al tiempo vuelve a reaparecer los períodos de acumulación de tensión y a cumplirse el ciclo.

En este tipo de violencia surgen también tres aspectos importantes que son:

1. Violencia psicológica: se relaciona con la intensidad creciente de la violencia, en este primer aspecto es sutil, se relaciona con lesiones en la autoestima de la mujer, ridiculizándola, agrediéndola emocionalmente, ignorándola, riéndose de sus opiniones: las consecuencias de este tipo de violencia no son tan visibles, provocan en la víctima un debilitamiento de las defensas psicológicas, la víctima se vuelve introvertida, deprimida y se muestra débil.

2. Violencia verbal: es el segundo aspecto, este refuerza la violencia psicológica, el agresor comienza a denigrar a la víctima poniéndole sobrenombres degradantes, insultándola, criticando el cuerpo, comienza a amenazarla con agresión física u homicidio; el agresor va creando un clima de miedo constante, la ridiculiza en presencia de otras personas, le grita, le culpa de todo; a partir de todas estas agresiones la víctima puede sentirse débil y deprimida.

3. Violencia física: comienza con apretones, pellizcones, sigue con cachetadas hasta llegar a las trompadas y puntapiés. Luego más tarde comienza a recurrir a objetos para provocarle daño y en medio de esta agresión le exige tener contactos sexuales. Esta escalada creciente puede terminar en homicidio o suicidio. La única manera de cortar con este ciclo de violencia creciente es a través de la intervención de alguna tercera persona. 
c) Mujeres maltratadas. Algunos especialistas prefieren referirse al síndrome de la mujer. Si bien hay un gran número de hombres golpeados, la gran mayoría de los casos atañe a personas de género femenino.

Desde el punto de vista estadístico ocurre en todas las edades pero se destaca en primer lugar entre las de 30 y 39 años, luego entre 20 y 29 años y más tarde entre las de 40 y 49 años, le sigue entre 15 y 19 años, para finalizar con las mayores de 50 . Las mujeres casadas constituyen un $66 \%$ del total, el resto lo componen novias, ex parejas, conocidas, amantes y amigas.

La mayor vulnerabilidad femenina no solo se debe a causas físicas, también al hecho de que las mujeres suelen concentrar en la mayoría de los casos, la carga y responsabilidad más acentuadas en la crianza de los/as hijos/as, además de que por diferentes cuestiones culturales condensan las tareas hogareñas y mantienen una mayor dependencia tanto económica como cultural con respecto a los hombres.

Una mujer que abandona su vivienda se encuentra en mayor riesgo que un varón, pero debe tenerse en cuenta que las mujeres que dejan a sus abusadores tienen un $75 \%$ más de riesgo de ser asesinadas por el abusador, que aquellas que se quedan conviviendo.

¿Por qué estas situaciones continúan? Existen dos corrientes básicas:

La postura tradicional, que plantea que las víctimas al vivir atemorizadas por represalias, por los golpes, por el posible retiro del sustento económico, por las órdenes irracionales y los permanentes castigos, manifiestan un estado general de confusión y desorganización. Las consecuencias son que llegan a sentirse ellas mismas culpables por la situación. No son conscientes de la educación patriarcal y machista que rige en la sociedad y que involucra directamente al varón.

Condena a la educación típica, es otra postura donde las mujeres aparecen en un lugar desventajoso, pero se detiene en los modos estructurales de relacionarse. No hay que confundir esta idea 
con un razonamiento contrario que sostiene que si una persona mantiene una relación, es porque le resulta placentera. Sin embargo, es evidente que una mujer golpeada no siente placer alguno, pero sí entran en juego componentes subjetivos tales, que en la práctica validan relaciones no placenteras.

d) Maltrato a los/as ancianos/as, se define como cualquier acto que por acción u omisión, provoque un daño físico o psicológico a un/a anciano/a por parte de la familia. Incluye agresión verbal, física, descuido de su alimentación, abuso financiero, amenazas por parte de los/as hijos/as o de otros miembros de la familia.

\section{VIOLENCIA URBANA.}

Existen factores sociales, políticos y religiosos que determinan los niveles de violencia en una comunidad, un país y el mundo. El descontento social, debido a las condiciones económicas puede ser factor determinante para el surgimiento de la violencia en las calles, en forma de delincuencia o explosiones sociales. Además, la sed de poder del hombre, lo ha llevado por el camino de derramamiento de sangre en la búsqueda del control político de naciones e imperios. Sin embargo, tal vez la razón que históricamente ha generado más violencia es la diferencia de conceptos religiosos, por las cuales se han desatado guerras y más recientemente, atentados terroristas devastadores.

La violencia se ha convertido en tema de cotidianidad, pues nos acompaña siempre bajo esquemas de escala social y resentimiento hacia los que tienen mayores posibilidades. Se ha hecho común que las personas hayan optado por "autoconfinamientos" debido al tema del enfrentamiento con la violencia, la cual no es más que el reflejo de una sociedad con pocas posibilidades de surgimiento.

"La peor consecuencia de la violencia es que nos estamos acostumbrando a ella".

\section{FASES DE LA VIOLENCIA.}

1. Fase de tensión creciente: acumulación diaria de tensiones causadas por situaciones conflictivas, las cuales son reprimidas o minimizadas bajo sentimientos de desesperanzas, disgusto y difusión. 
2. Fase de explosión: la acumulación y represión de tensiones se concentran en un solo momento, cuando la persona estalla emocionalmente por medio de actos violentos o agresiones físicas, verbales, emocionales o sexuales.

3. Fase de remordimiento: la culpa consume al victimario al darse cuenta de la agresión perpetrada, quien en un primer momento se excusa por sus actos, lo que causa un daño irreparable a su autoestima, y facilita el inicio de estas tres fases cíclicas.

\section{CRISIS EN LAS FAMILIAS.}

Cuando la familia empieza a funcionar con predominio de desorden y comienza a haber situaciones que exceden su límite de tolerancia, estos integrantes de la familia han entrado en lo que comúnmente se denomina una "crisis".

Es preciso definir lo que se entiende por Crisis: supone la aparición brusca de síntomas, generalmente en respuesta a un estrés, que incide en una ruptura del ciclo vital del individuo y en la que intervienen factores personales y ambientales. Se desencadena, cuando ante un estrés grave, un problema serio o una situación amenazante, los mecanismos habituales del individuo para afrontar problemas y buscar soluciones, no cumplen con sus posibilidades. Se produce un desequilibrio entre la importancia y dificultad del problema y los recursos de que dispone para enfrentarlos.

La crisis sería un período de transición a partir del cual puede que se desarrolle un trastorno mental porque el individuo se enfrentó al conflicto de forma desadaptada; o al contrario, puede superarla satisfactoriamente saliendo fortalecido y más capacitado para afrontar futuras dificultades, ya que supo buscar nuevas perspectivas y enfoques.

Esta crisis se va a caracterizar por estados de confusión, desorganización y caos. Es inminente un cambio significativo, esto significa "peligro" y "oportunidad". El peligro está en la adopción de actitudes o soluciones que lleven a la pérdida y la oportunidad está en la posibilidad de encontrar alternativas que conduzcan al crecimiento, aún en medio del dolor. Toda crisis es una oportunidad que encierra peligro. 
La naturaleza de la crisis es muy diversa: puede surgir como respuesta a un suceso traumático: fallecimiento de un ser querido, separación conyugal, quiebra económica, problemas laborales, intentos de suicidio, descompensaciones de un miembro de la familia con trastornos graves de personalidad e incluso puede entenderse, en un sentido más amplio, como un momento de tránsito vital.

\section{PROTECCIÓN CONTRA LA VIOLENCIA FAMILIAR.}

\section{"EL CRIMEN OCULTO"}

La Ley permite que cualquier persona que ha sufrido maltrato o lesiones físicas de los integrantes de un grupo familiar, denuncie los hechos y solicite las medidas cautelares conexas.

Estas medidas cautelares se refieren al pedido de exclusión del agresor de la vivienda familiar; la prohibición de que acceda al domicilio, lugar de trabajo o estudio de la víctima y por último, reintegro de la víctima, con exclusión del agresor. La duración de estas medidas será establecida por la autoridad competente que entienda la causa.

En el caso de que las víctimas de violencia fueran menores o incapaces, la ley establece la obligación de denunciar y ella recae sobre los representantes legales (padres, tutores, guardadores). También están obligados a denunciar los integrantes de servicios públicos 0 privados y profesionales de la salud.

La actual Constitución Política del Estado contempla un principio consagrado en el artículo 23, numeral 3 que dice:

La igualdad ante Ley. Todas las personas serán consideradas iguales y gozaran de los mismos derechos, libertadores y oportunidades, sin discriminación en razón de nacimiento, edad, sexo, etnia, color, origen social, idioma, religión, filiación política, posición económica, orientación sexual, estado de salud, discapacidad o de diferencia de cualquier otra índole.

Pero a pesar de ese reconocimiento constitucional, las estadísticas demuestran gran cantidad de casos sobre el maltrato familiar 
sobre todo a la mujer, problema complejo incrustado en la sociedad, violencia que no solamente implica la aplicación de sanciones al agresor o agresores sino que se hace indispensable programas especiales de difusión para obtener un cambio en la mentalidad respecto a los valores, rol social y sexual desempeñados tanto por hombres como por mujeres.

Existen otros soportes legales como: Ley contra la violencia a la mujer y la familia, promulgada en el año 1995; Convención Interamericana para prevenir, sancionar y erradicar la violencia contra la mujer, relacionados con los derechos humanos de las mujeres; aprobación del Proyecto Subregional de la violencia intrafamiliar contra la mujer en Centroamérica, año 1995; el 9 del Septiembre de 1994 se publicó la Ley de Maternidad Gratuita y Atención a la Infancia que posteriormente fuera reformada por la Ley 129 publicada en el Registro Oficial № 381 del 10 de Agosto de 1998 y un sinnúmero de proyectos contra la violencia familiar buscando la intervención de la comunidad.

Existe además la Comisaría de la Mujer y la Familia, con la finalidad de apoyar a la víctima de la agresión y dejar evidencia la realidad oculta existente debido a la discriminación y al miedo, a fin de apoyarla de manera decidida contra estos delitos. En nuestro país esta comisaría fue creada en el año 1994 para prevenir y atender las denuncias de maltratos, lesiones, injurias y delitos.

En esta dependencia, formada por varios profesionales, y que constituye una unidad interdisciplinaria, se da también orientación psicológica de acuerdo a las necesidades de la víctima, a la vez que proporciona a las mujeres las herramientas que les permitan enfrentar la violencia de la que son víctimas y ayudarlas a que rescaten sus potencialidades y habilidades a fin de que recuperen su autoestima para lograr vivir una vida plena. Se trata de dar facilidades a quienes por falta de medios económicos, desconocimiento o falta de apoyo moral, no pueden determinar la agresión, brindarles apoyo emocional y legal para enseñarles a enfrentar y combatir la violencia.

No es fácil salir de una relación de agresión, pero siempre hay una esperanza ya que una vida sin violencia es una vida digna, y en 
esta forma estaremos contribuyendo al desarrollo del país y al desarrollo armonioso de una familia, por lo tanto, digamos NO a la violencia que destruye nuestra familia. Todo ser que es agredido física y psicológicamente no logra ver el mundo y las posibilidades que este le ofrece, por ello, luchemos por la erradicación de la violencia familiar para lograr un modelo de familia unida, equitativa y feliz.

\section{La pobreza no tiene que ser una barrera que impida sancionar al o la agresor(a) que promueva la violencia en la familia.}

\section{TRATAMIENTO}

La noción misma de crisis familiar conlleva la urgencia y la necesidad de una intervención terapéutica. Esta intervención se centra en la acción de un equipo multidisciplinario, donde trabajen profesionales de varias disciplinas dando ayuda inmediata. Es muy importante proporcionar asistencia allí donde se produjo la crisis, además hay que ofertar una continua disponibilidad. El enfoque se centrará en el problema y situación actual y se tiene que procurar mantener la integridad del grupo familiar así como estimular sus mecanismos positivos para afrontar del estrés.

Debemos considerar tres objetivos principales en la intervención de la crisis:

1 Definir la naturaleza del problema.

I Implicar al sujeto y su entorno sociofamiliar, si es posible, en la búsqueda de soluciones al conflicto.

I Valorar la necesidad de un tratamiento individual / familiar más a largo plazo si fuese necesario.

En última instancia, la intervención en la crisis es la de la prevención secundaria, que involucra al individuo, la familia y el entorno. Se evaluará precozmente el conflicto, mediante técnicas terapéuticas específicas para evitar así el desarrollo de complicaciones posteriores. El individuo en crisis está incluido en un contexto familiar y social, por lo que el abordaje ha de ser global: es necesario conocer la dinámica y estructura de la familia, su actitud hacia el miembro referido como paciente, su manera de afrontar crisis 
anteriores y los posibles factores de cambio o de conflicto que hayan podido ocurrir.

La descomposición familiar puede considerarse desde una doble óptica:

1. Cuando es toda la familia la que experimenta un estrés vital, sin que haya un único paciente identificado, por ejemplo en el caso de la muerte de una familiar.

Cuando, frente a un paciente identificado, toda la familia participa del malestar y sufrimiento del individuo en crisis o de las consecuencias de sus actos e incluso puede ocurrir que los problemas de este reflejen los de la familia. Así, puede suceder que la inminencia de un cambio en la familia, la alteración en la comunicación o la aparición de conflictos entre sus miembros, suponga una ruptura del equilibrio intrafamiliar y la descompensación psicológica de uno de los miembros más vulnerable en esos momentos. Es necesario ofrecer un espacio en el que puedan formular preguntas, expresar sus preocupaciones, miedos, sentimientos de culpa, de impotencia y otros.

En una situación de urgencia las familias experimentan un gran estrés, que puede aumentar si se sienten ignorados o poco apoyados; en estas condiciones las actitudes pueden variar desde el enfado, irritabilidad, hostilidad franca hasta nula colaboración. Con la primera entrevista o primer contacto, se intenta por una parte aliviar la ansiedad del grupo familiar ante una emergencia y por otra, analizar la dinámica familiar así como su actitud hacia el paciente. Es importante valorar si los problemas del paciente son producto de un conflicto intrapersonal o son un reflejo de los de familia.

La terapia familiar recae sobre el actuar y dramatizar los estados emotivos y conflictivos en el presente, para verificar diferentes posibilidades de cambio en el interior del sistema familiar. El terapeuta trata que la familia se comporte dentro de la sesión de la misma manera que lo hacen en su casa. El terapeuta consigue que los miembros de la familia interactúen, para discutir problemas que consideran disfuncionales y puedan zanjar desacuerdos. 
Durante la terapia se va construyendo una nueva historia, en la que se plantean los límites individuales mediante un intento de redefinición de las respectivas funciones y de los espacios personales, el terapeuta representa el nuevo nexo que hace de catalizador en la búsqueda de nuevos itinerarios relacionales.

Las mujeres víctimas de maltrato o violadas pueden participar de terapia individual o grupal, la finalidad de estas terapias en estos casos es lograr que se sientan supervivientes y no víctimas o humilladas. La terapia les ha de permitir:

1 Manejar el trauma.

1 Establecer una sensación de control sobre su cuerpo.

1 Mejorar la autoestima.

1 Dejar de sentirse solas y aisladas.

La terapia de grupo:

1 Brinda el mejor sistema de apoyo, permitiendo compartir el trauma, establecer buenas relaciones con los otros miembros del grupo.

1 Aleja los sentimientos de desesperanza.

1 Aumenta el sentimiento de auto eficacia.

\section{TIPOS DE DENUNCIAS RECEPTADAS}

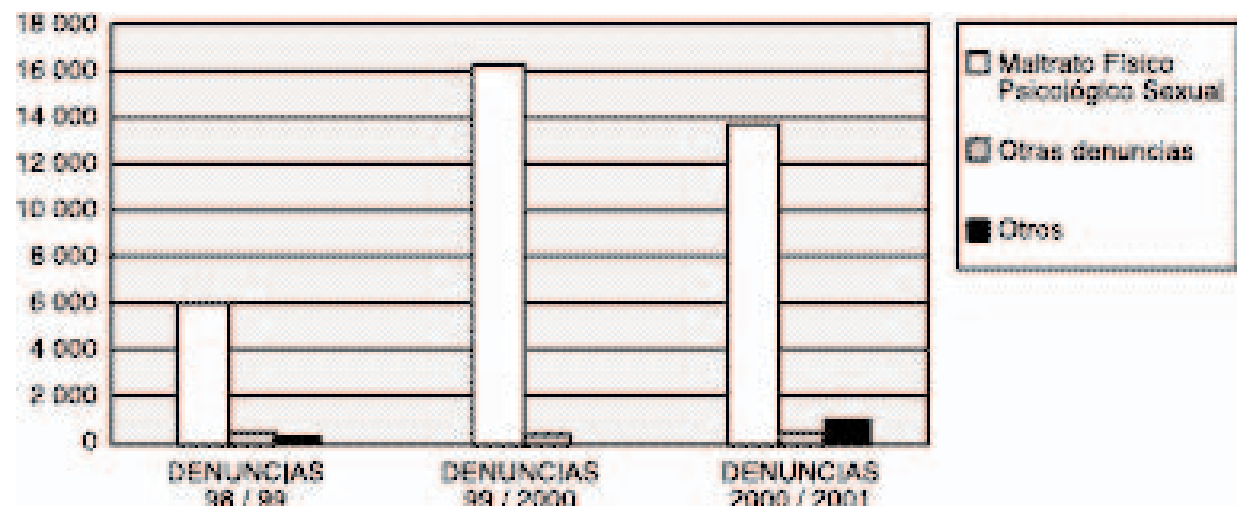

(*) Estadística de la Dirección Provincial de Salud del Guayas y Comisaría de la Mujer y la Familia. Manual de Terapia Racional Emotiva - Albert Ellis - 3ra. Edición 


\section{AGRESIONES PSICOLÓGICAS}

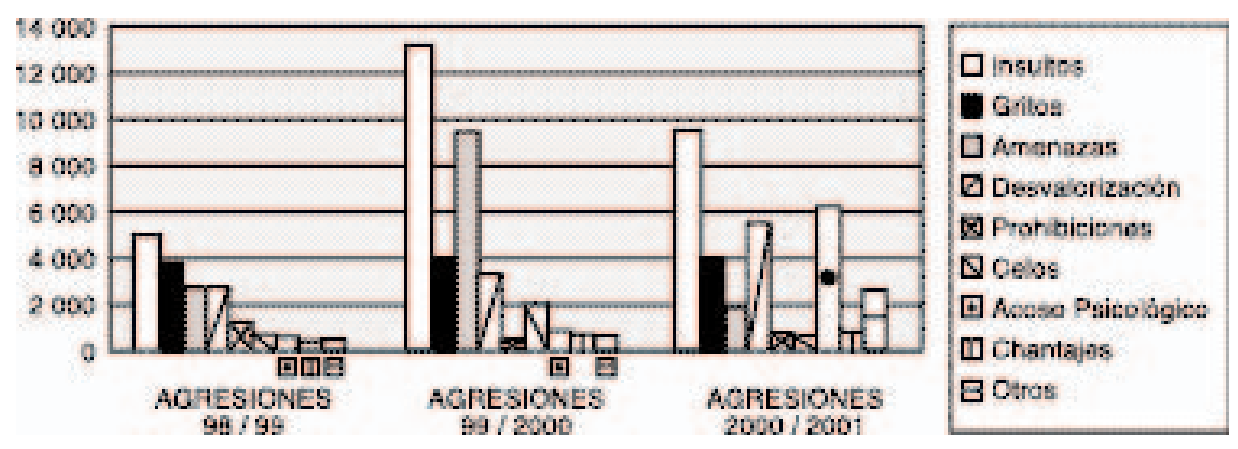

(*) Estadística de la Dirección Provincial de Salud del Guayas y Comisaría de la Mujer y la Familia. Manual de Terapia Racional Emotiva - Albert Ellis - 3ra. Edición.

\section{TIPOS DE AGRESIONES FÍSICAS}

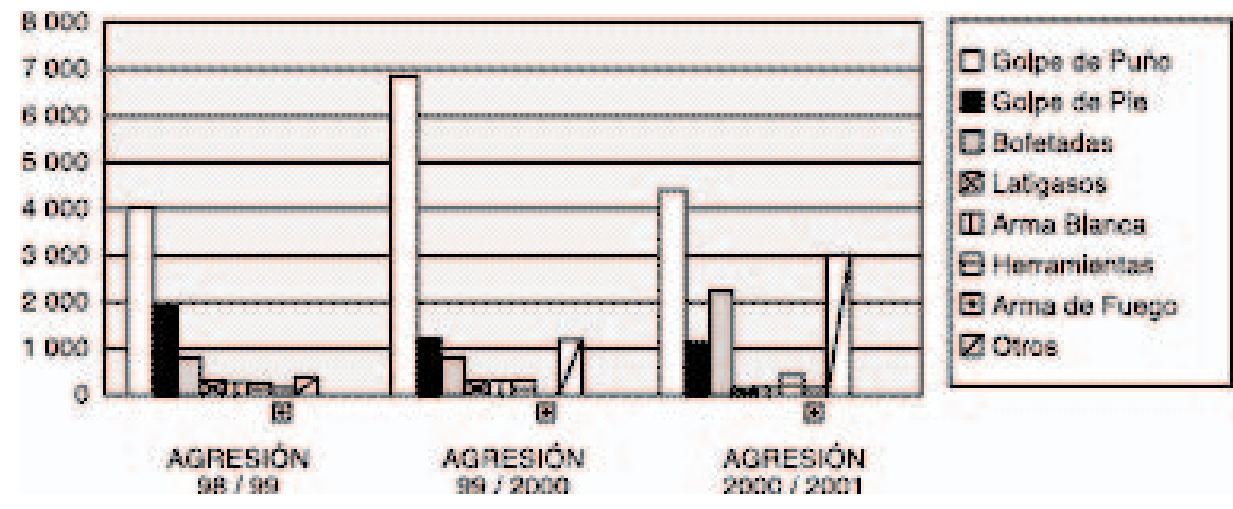

(*) Estadística de la Dirección Provincial de Salud del Guayas y Comisaría de la Mujer y la Familia. Manual de Terapia Racional Emotiva - Albert Ellis - 3ra. Edición. 


\section{AGRESIONES SEXUALES}

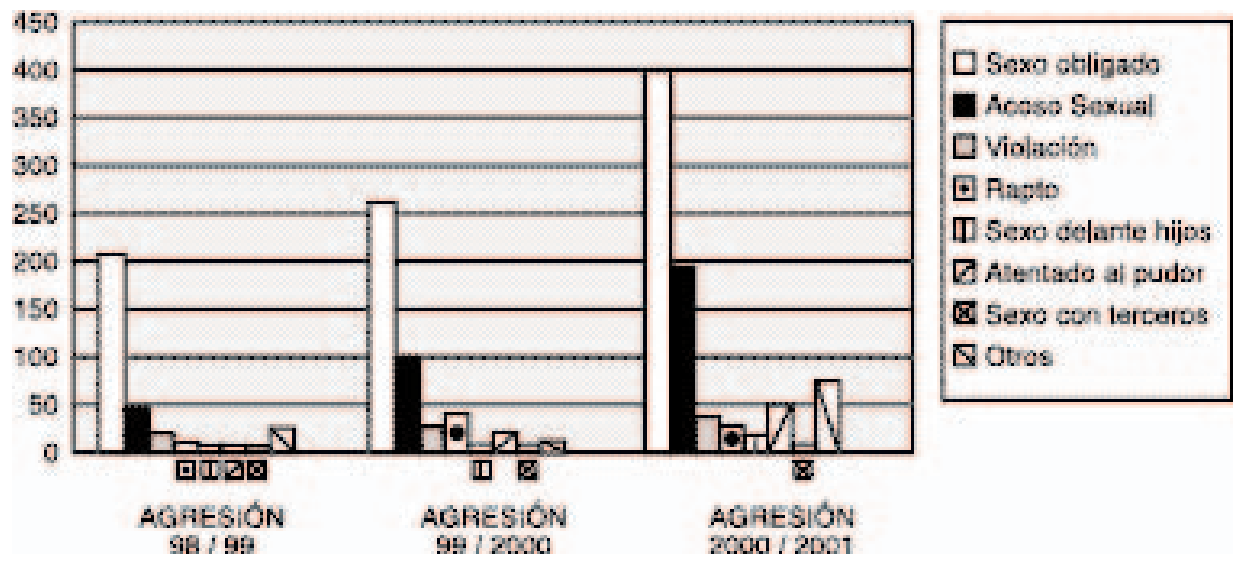

(*) Estadística de la Dirección Provincial de Salud del Guayas y Comisaría de la Mujer y la Familia. Manual de Terapia Racional Emotiva - Albert Ellis - 3ra. Edición.

\section{REACCIÓN DE LA MUJER ANTE LA AGRESIÓN}

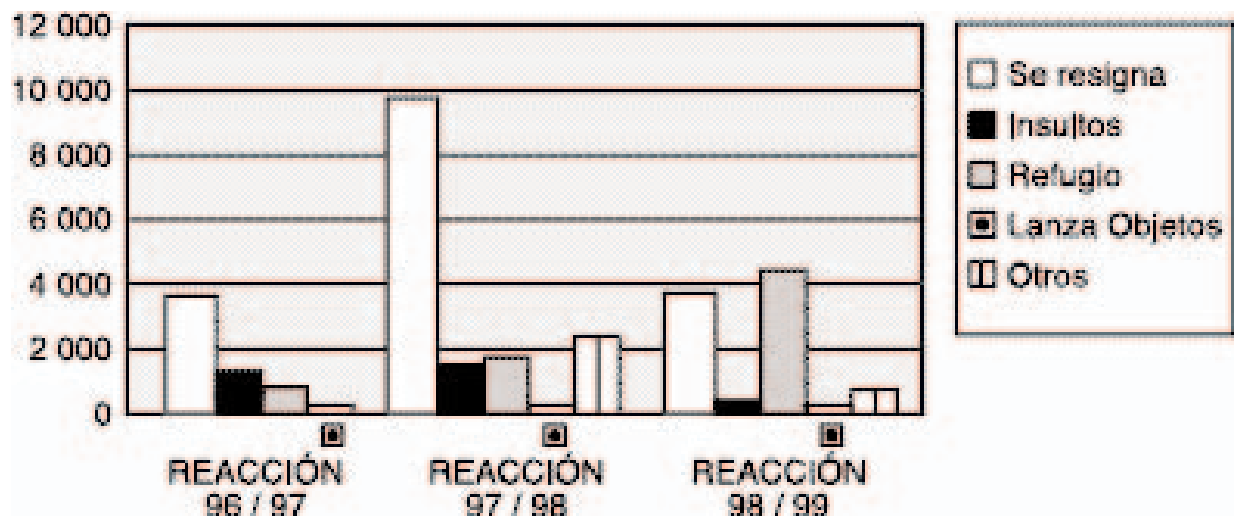

(*) Estadística de la Dirección Provincial de Salud del Guayas y Comisaría de la Mujer y la Familia. Manual de Terapia Racional Emotiva - Albert Ellis - 3ra. Edición. 


\section{VIOLENCIA Y MALTRATO}

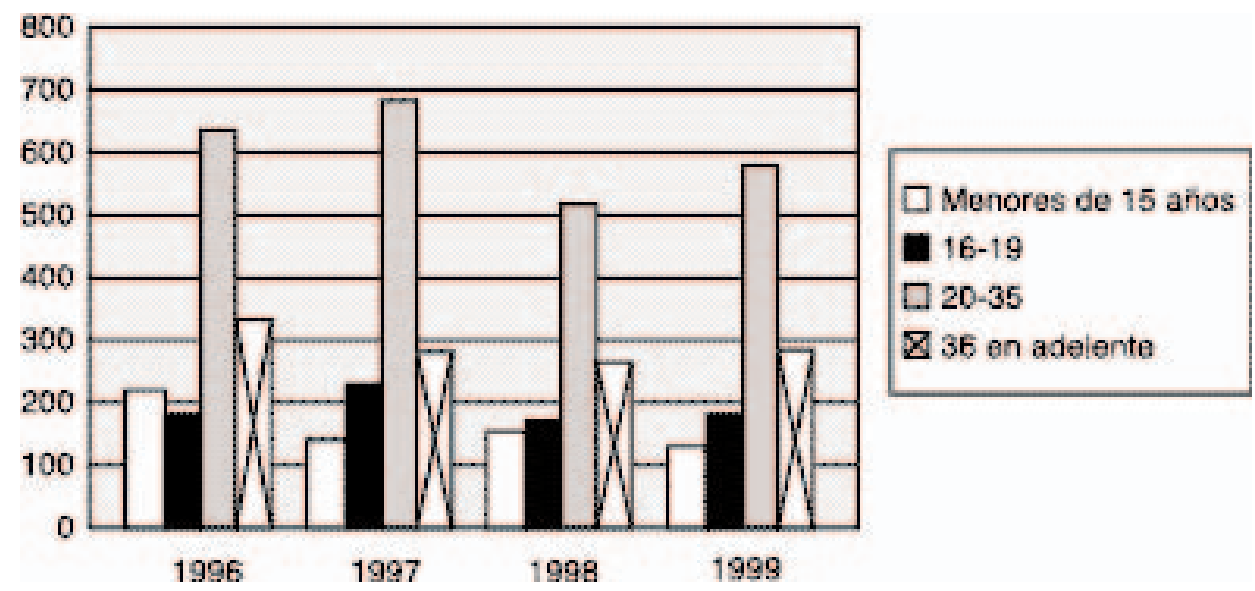

(*) Estadística de la Dirección Provincial de Salud del Guayas y Comisaría de la Mujer y la Familia. Manual de Terapia Racional Emotiva - Albert Ellis - 3ra. Edición.

\section{INSTRUCCIÓN DE LOS AGRESORES}

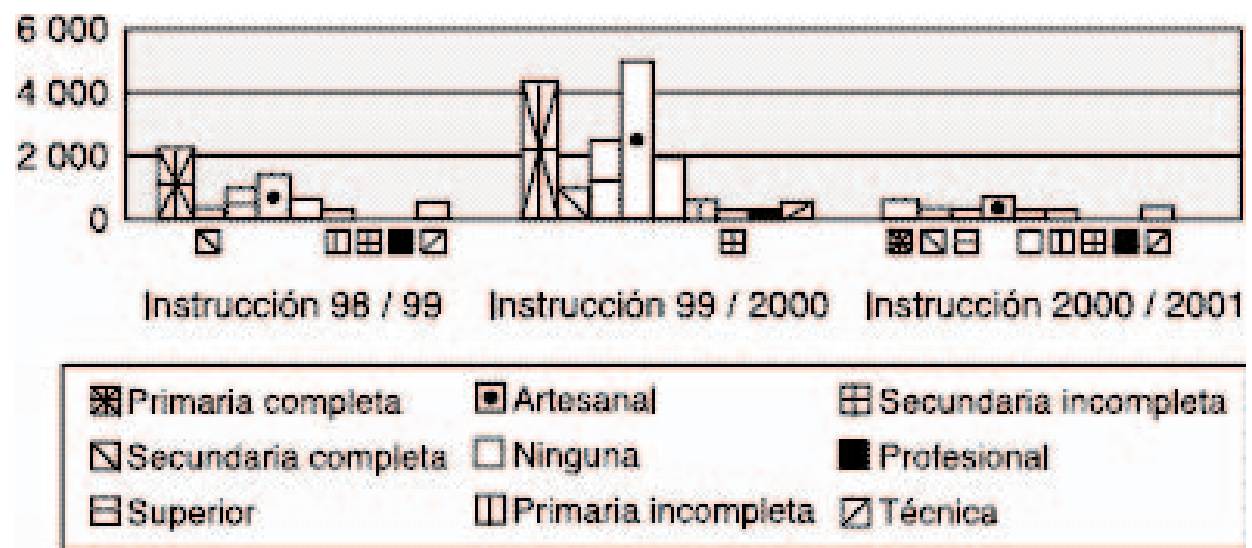

$\left(^{\star}\right)$ Estadística de la Dirección Provincial de Salud del Guayas y Comisaría de la Mujer y la Familia. Manual de Terapia Racional Emotiva - Albert Ellis - 3ra. Edición. 


\section{INSTRUCCIÓN DE LAS AGREDIDAS}

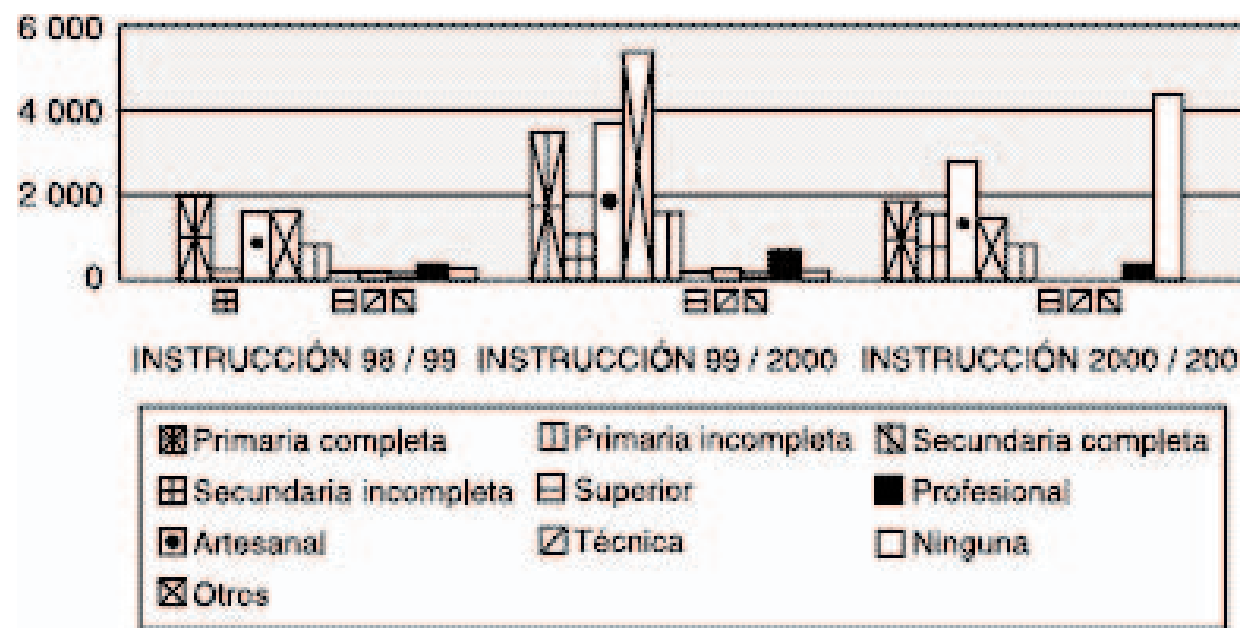

$\left(^{*}\right)$ Estadística de la Dirección Provincial de Salud del Guayas y Comisaría de la Mujer y la Familia. Manual de Terapia Racional Emotiva - Albert Ellis - 3ra. Edición.

\section{SEXO DE LAS PERSONAS AGREDIDAS}

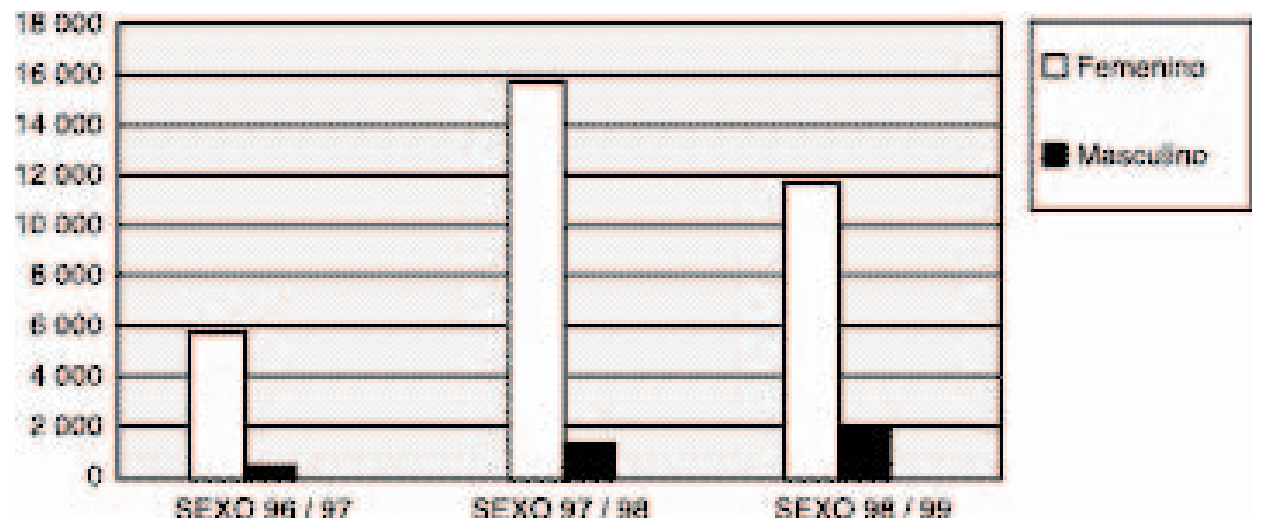

(*) Estadística de la Dirección Provincial de Salud del Guayas y Comisaría de la Mujer y la Familia. Manual de Terapia Racional Emotiva - Albert Ellis - 3ra. Edición. 